\section{Revised ozone standard angers environmentalists}

The US Environmental Protection Agency (EPA) is once again under fire for ignoring its science advisers - this time in setting a new air-quality standard for ozone, a primary component of smog.

The agency's decision on 13 March will reduce the current regulatory limit on ground-level ozone concentrations, set in
1997, from a maximum of 84 parts per billion (p.p.b.) to 75 p.p.b.. An agency advisory panel had recommended a range of 60 to 70 p.p.b..

Environmentalists also criticized what they saw as White House interference. In a 6 March memorandum, a top White House regulatory official, Susan Dudley, urged the EPA not to set a secondary "welfare" standard at a lower level to protect against other environmental problems, including potential damage to crops and other vegetation. In the end, the EPA set the primary and

\title{
Wellcome awards reveal microscopic masterpieces
}

This picture of sperm developing in a testis is one of 23 winning images in the 2008 Wellcome Image Awards, which focus on the visual wonder of the microscopic world.

The cell nuclei are shown in blue and the mitochondria appear red in this striking image taken by Kate Sullivan, an electron microscopist at the Medical Research Council's National Institute for Medical Research in London. The tails of the sperm are pointing inwards.

Other images from the competition, including a fly standing on sugar crystals and an array of vitamin $\mathrm{C}$ crystals, can be found at www.wellcome.ac.uk/en/ wia/gallery.html.

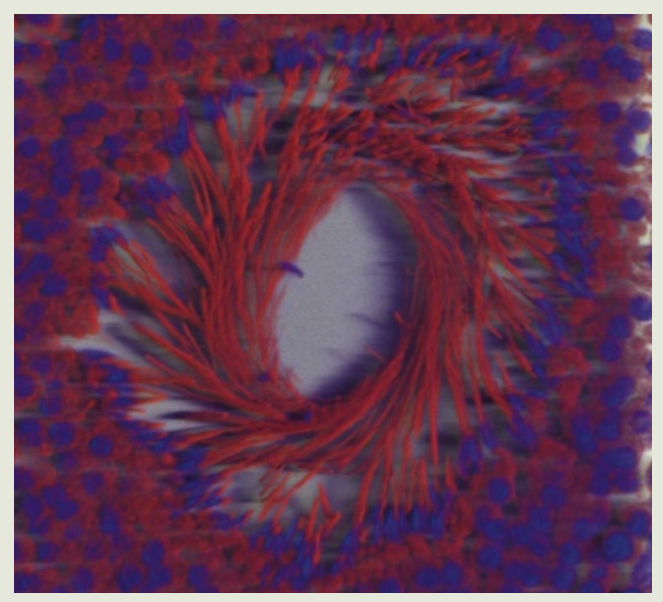

secondary standards at the same level.

The air quality in an estimated 345 municipalities and counties could be in violation when the new standards come into effect in 2010.

\section{Fresh safety concerns for popular anaemia drugs}

A panel of advisers to the US Food and Drug Administration (FDA) last week recommended restricting the use of several blockbuster anaemia drugs in cancer patients.

The drugs, which promote the production of red blood cells, are Aranesp and Epogen, sold by Amgen, and Procrit, sold by Johnson \& Johnson. These medicines are the subject of safety concerns after recent trials linked them to shortened cancer survival times and increased tumour growth.

The advisers voted overwhelmingly to keep the drugs on the market for treatment of anaemia induced by chemotherapy, but said that they should be used only with specific cancers. They voted by a majority of nine to five to bar the drugs' use in patients with head and neck, and breast cancers, for which studies had raised particular safety concerns.

The FDA is not bound to implement its advisers' recommendations, but it often does. 